\title{
Guerra internacional, revolución y dictadura: los partidos parlamentarios y la política peruana entre 1865 y $1867^{*}$
}

\section{International War, Revolution, and Dictatorship: Parliamentary Parties and Peruvian Politics between 1865-1867}

VÍCTOR PERALTA RUIZ

Consejo Superior de Investigaciones Cientificas

victor.peralta@cchs.csic.es

\section{RESUMEN}

Este artículo estudia el comportamiento politico de los primeros partidos parlamentarios del Perú entre el gobierno constitucional del general Juan Antonio Pezet y la dictadura del general Mariano Ignacio Prado. Se argumenta que la opción por la revolución en 1865 y 1867 estuvo condicionada por la forma en que el gobierno condujo el conflicto diplomático con España, en el primer caso, y en cómo la dictadura procesó los réditos políticos de la jornada naval del 2 de mayo de 1866, en el segundo caso. Es decir, a diferencia de otros paises implicados en la cuestión española, la guerra internacional condicionó el sistema politico peruano y es un factor explicativo de la actuación golpista de sus principales partidos parlamentarios al sentirse estos coyunturalmente excluidos por el poder ejecutivo.

Palabras clave: revolución; siglo XIX; Perú; Juan Antonio Pezet; Mariano Ignacio Prado

\footnotetext{
* Investigación realizada dentro del proyecto I+D HAR2016-77609-P, «El poder legislativo en la disputa por la revolución. América Latina 1821-1860», financiado por el Ministerio de Ciencia, Innovación y Universidades.
}

HISTORIOA XLII.1 (2018): 85-114 / ISSN 0252-8894

https://doi.org/10.18800/historica.201801.003 


\section{ABSTRACT}

This article studies the political behavior of the first Peruvian parliamentary parties between the constitutional government of General Juan Antonio Pezet and the Dictatorship of General Mariano Ignacio Prado. I argue that the revolutionary option in 1865 and 1867 was conditioned by the way the government conducted its diplomatic conflict with Spain, in the first case, and by how the dictatorship made use of the political gains of the naval conflict of May 2 1866, in the second. That is to say, unlike other countries involved in the Spanish diplomatic question, international war conditioned the Peruvian political system. In particular, international war becomes an explanatory factor for the main parliamentary parties' coup intentions, having felt circumstantially excluded by the executive office.

Keywords: revolution; XIX century; Peru; Juan Antonio Pezet; Mariano Ignacio Prado

E las relaciones internacionales de América Latina en el siglo XIX
ocupa un lugar destacado el prolongado diferendo que mantuvo España con sus antiguas posesiones territoriales después de proclamar estas sus independencias. Uno de los momentos más trascendentales fue la contienda internacional en que se vio envuelta la España de Isabel II con México, Santo Domingo, Chile y Perú en la primera mitad de la década de 1860. En estos dos últimos casos el asunto estalló cuando la expedición científica española emprendida en 1862, abruptamente, se transformó en 1864 en una ofensiva naval dispuesta a recurrir a la agresión armada para resolver las desavenencias diplomáticas. En Chile, esta ofensiva de la escuadra española si bien causó malestar social no afectó el desenvolvimiento de su política interior. Gracias a su política de reconciliación regional, el gobierno liberal de José Joaquín Pérez obtuvo la aprobación incondicional de los partidos parlamentarios en el diferendo internacional. ${ }^{1}$ Apoyado en este consenso, Chile declaró la

${ }^{1}$ El grave conflicto político vivido en los años cincuenta bajo el gobierno de Manuel Montt se apaciguó con José Joaquín Pérez porque las provincias más rebeldes a la 
guerra a España el 24 de septiembre de 1865 y firmó el tratado ofensivo y defensivo con Perú el 5 de diciembre de 1865, acuerdo al que se sumaron después Bolivia y Ecuador. En el caso del Perú ocurrió lo contrario a la unitaria reacción nacionalista experimentada por la política chilena. El desenvolvimiento de su política interior entre 1865 y 1867 , con el estallido de una revolución y la imposición de una dictadura, iba a estar profundamente marcado por este conflicto internacional.

El planteamiento de este estudio resalta el impacto del diferendo internacional con España en la forma de actuar de los primeros partidos parlamentarios. En un artículo pionero, Ulrich Mücke propuso denominar así a las iniciales agrupaciones políticas electorales y realizó una aproximación cuantitativa al comportamiento de los congresistas durante la década de 1860 y $1870 .^{2}$ En la presente investigación se privilegia el análisis cualitativo, es decir, la praxis de los partidos parlamentarios bajo los gobiernos de Juan Antonio Pezet y Mariano Ignacio Prado. Se argumenta como hipótesis de trabajo que la actuación de los partidos parlamentarios más importantes en 1865 estuvo enmarcada en la justificación de la revolución como forma de combatir su exclusión de la cuestión española. La lógica excluyente fue practicada en 1851 por el presidente Rufino Echenique, lo que supuso apartar al adversario parlamentario de los espacios políticos "patrimonializados» por el gobierno central. ${ }^{3}$ Esta actitud dio lugar a que los líderes políticos de los partidos que se sintieron políticamente excluidos recurrieran a la revolución

autoridad de Santiago fueron integradas por este mandatario tanto al Congreso como al poder central; véase Saldaña Lagos 2010.

2 Mücke definió los partidos parlamentarios de la década de 1860 como «grupos de miembros del Congreso que votan de manera homogénea dentro de un periodo legislativo» (2004: 118).

3 La actuación excluyente de Echenique contrastó con los acuerdos clientelares durante la era del guano practicados por el modelo «autoritario-constitucional» del general Ramón Castilla con liberales y conservadores (Mc Evoy 1996). La debacle del régimen echeniquista de 1855 se relaciona con la utilización de los réditos derivados de la exportación del guano en la consolidación de la deuda interna, proceso que estuvo rodeado de un grave escándalo de corrupción que benefició exclusivamente a personajes de su entorno partidario (Quiroz 1987). 
para imponer sus objetivos (fue el caso de Ramón Castilla y Domingo Elías en 1854, y de Manuel Ignacio de Vivanco en 1856). ${ }^{4}$ Siguiendo esta lógica contestataria, la revolución liderada por el general Mariano Ignacio Prado, que conllevó el establecimiento de una dictadura el 25 de noviembre de 1865 , fue el efecto directo de la crisis política y diplomática con España polémicamente administrada por el gobierno del general Juan Antonio Pezet. En el contexto del referido vínculo entre guerra internacional y revolución, la dictadura de Prado se propuso rentabilizar políticamente la gesta del 2 de mayo de 1866 para auspiciar un Congreso que promulgara una Constitución liberal, como la de 1856, y que legitimara su conversión en presidente constitucional. Pero el dictador cometió el error de excluir a todos sus adversarios políticos de dicha asamblea. El derrocamiento de Prado en enero de 1868 por un levantamiento popular liderado por el coronel José Balta y el general Pedro Diez Canseco confirmó la vigencia de la vía revolucionaria como forma predilecta de actuación de los iniciales partidos parlamentarios descontentos con su real o supuesta marginación política.

\section{EL CAMINO HACIA LA FRACTURA DE LOS PARTIDOS PARLAMENTARIOS} (I 862-I 865)

En 1862 el diario El Comercio publicó por entregas la Historia de los partidos de Santiago Távara. Este recorrido lo inició con el Protectorado de San Martín y lo concluyó con la elección del general Miguel San Román en 1862. El autor concibió el concepto de partido bajo su connotación negativa de facción o lucha ideológica y pasional, «sin que necesariamente los actores históricos se reconocieran a sí mismos o se les designara de tal modo». Távara no advirtió que lo que por entonces se denominaban como cofradías, clubes o sociedades electorales eran el antecedente institucional de los partidos modernos. La presencia de estas agrupaciones políticas desde la campaña presidencial de 1850,

4 Para la revolución de 1854, véase Pinto Vallejos 2016 y Peralta Ruiz 2013; para la revolución de 1856, Sobrevilla Perea 2005 y Peralta Ruiz 2018.

5 Aljovín de Losada 2010: 79. 
según José Ragas, no solo canalizó la participación de los ciudadanos votantes sino que «se puede deducir que en los pueblos donde se contó con estas organizaciones, la acción proselitista dio como resultado una alta concentración de votos a favor del candidato o incluso la victoria por amplio margen». ${ }^{6}$ En otras palabras, los primeros partidos parlamentarios electoralmente competitivos se plasmaron al principio de la década de 1850. La necesidad de incluir a estos actores políticos en la reflexión historiográfica conduce necesariamente a priorizar el estudio de la relación subordinada o conflictiva del legislativo con el ejecutivo. ${ }^{7}$

Según la Constitución moderada de 1860, el Congreso ordinario se elegía y reunía cada dos años y su duración debía ser de cien días útiles. ${ }^{8}$ La ley electoral que normó la elección presidencial, legislativa y municipal de 1862 dispuso la celebración de elecciones parroquiales el segundo domingo de octubre de 1861 y el establecimiento del colegio provincial para la votación de diputados y senadores propietarios, así como de alcaldes, el 15 de noviembre de 1861. ${ }^{9}$ Esta reglamentación estuvo precedida de la formación de un nuevo registro cívico de electores formado a partir de un censo general de población. Los elegidos por los colegios de provincias al parlamento debían sumar un total de 104 diputados propietarios y 42 senadores. ${ }^{10}$

La agrupación política castillista controló casi en solitario la mayoría de las mesas de sufragio y cuando el Congreso se estableció el 28 de julio de 1862 sus representantes apoyaron de forma unánime la nominación presidencial del general Miguel de San Román. En opinión de Santiago Távara, el presidente saliente confió «en el carácter moderado de su candidato [San Román] para dar un segundo ejemplo de un Presidente

6 Ragas Rojas 2003: 96.

7 Rabasa 1999, Gentile 2008, Sobrevilla Perea 2017 y Irurozqui 2018.

8 El fracaso del proyecto de Constitución corporativo-autoritaria de Bartolomé Herrera allanó el camino para una transacción entre conservadores y liberales que permitió conferir un carácter moderado a la Constitución de 1860.

9 «Ley electoral del 4 de abril de 1861», en Constitución 1863: 71-88.

${ }^{10}$ Benvenuto 1906-1955, VI. 
cívico-militar». ${ }^{11}$ En su dilatada trayectoria política, San Román fue leal a generales de tendencia conservadora como Agustín Gamarra, Pedro Bermúdez o Juan Crisóstomo Torrico. Pero cuando el general Castilla emergió como líder político desde 1845, San Román se convirtió en un leal servidor suyo en su condición de ministro, diputado y general en jefe del ejército que combatió a los generales conservadores en las dos guerras civiles de los años cincuenta. Castilla creyó que su influencia sobre San Román estaba absolutamente garantizada al acompañar a este como primer y segundo vicepresidentes, respectivamente, los generales Juan Antonio Pezet (su exministro) y Pedro Diez Canseco (su cuñado).

Pero Castilla erró al pensar que su sucesor continuaría dócilmente su desempeño político. Las primeras decisiones de San Román más bien alarmaron al exmandatario al permitir este el retorno del exilio de sus más recalcitrantes adversarios, esto es, los generales Echenique y Vivanco así como el político liberal «rojo» José Gálvez. El flamante gobernante, en su afán de primar el carácter reconciliador de su mandato, se distanció del partido que lo apoyó electoralmente y con ello propició los primeros enfrentamientos entre el ejecutivo y el legislativo. ${ }^{12}$ Para empeorar esta situación, mientras el Congreso asumió una actitud crítica contra varios actos del fenecido régimen castillista, el ejército readmitió como oficiales a personajes vinculados al echeniquismo y al vivanquismo. Ante estos imponderables, Castilla se retiró de la política para probar fortuna en una serie de actividades económicas, pero el inesperado fallecimiento de San Román el 3 de abril de 1863 dio motivo para su retorno a la escena política y, como resultado de ello, a la inauguración de una etapa de dura pugna entre los partidos parlamentarios.

Entre abril y agosto de 1863, el general Diez Canseco, en su condición de segundo vicepresidente, asumió provisionalmente la presidencia a la espera de que el general Pezet retornara de su estancia en Europa. Una polémica decisión de Diez Canseco en el breve tiempo que estuvo en el poder fue nombrar al general Vivanco como ministro plenipotenciario

11 Távara 1951: 182.

12 Aljovín de Losada 2014: 61. 
en Chile. Esta designación estrechó el vínculo del vivanquismo con el gobierno pero a la vez avizoró el desplazamiento parlamentario de los castillistas. Diez Canseco confirmó la decisión inaugurada ya por San Román de entregar importantes prefecturas a connotados vivanquistas (como el general Ramón Vargas Machuca en Arequipa) o echeniquistas (como el coronel Manuel Vargas Guimet en Lima). ${ }^{13}$ Bajo este condicionante de sus dos antecesores de gobernar con la colaboración de antiguos adversarios políticos de Castilla, Pezet asumió la presidencia el 5 de agosto de 1863 .

La sinuosa trayectoria política de Pezet explica su fácil adaptación al modo de gobernar de San Román y de Diez Canseco. Desde los años treinta, este militar demostró lealtad a una serie de gobernantes incluso enfrentados ideológicamente entre sí, como fueron los generales Gamarra, Orbegoso, Vidal, Vivanco, Echenique y Castilla. A lo largo de su vida ejerció cargos importantes como mandatario interino, prefecto y diputado, pero también experimentó varios destierros. Su último exilio se había producido a Chile tras apoyar a Vivanco en la guerra civil de 1858, pero al poco tiempo Castilla lo perdonó y lo nombró ministro de Guerra y Marina, presidente del Consejo de Ministros y jefe del estado mayor del ejército que invadió Ecuador en noviembre de $1859 .{ }^{14}$ Pezet se convirtió así en una pieza clave del entramado clientelar confeccionado por el general Castilla durante su presidencia provisoria (1854-1858) y su presidencia constitucional (1858-1862).

Al iniciar su gobierno, Pezet, como San Román, consideró que su fidelidad al castillismo debía pasar a un segundo lugar si de lo que se trataba era de apaciguar los pleitos y conspiraciones promovidas por los distintos clanes políticos enemistados. Así resumió la postura de Pezet un anónimo apologista suyo: «no habiéndose podido sostener dos administraciones consecutivas en el Perú, era para él evidente la importancia vital de hacer todo género de esfuerzos y sacrificios para que la suya pasase en calma, y abriese pacífica y legalmente el camino a otra

\footnotetext{
13 Diez Canseco 1950: 170-171.

${ }^{14}$ Arias-Schreiber Pezet 1963.
} 
administración constitucional». ${ }^{15}$ Su primera decisión fue nombrar un consejo de ministros consensuado con los tres líderes políticos militares (Castilla, Echenique y Vivanco). Su política de consenso explica la relativa tranquilidad política que se experimentó en el país. A modo de ejemplo, el mayor conflicto que enfrentó el mandatario fue no apoyar la candidatura como diputado por El Callao del general Castilla durante la elección provincial al Congreso celebrada en noviembre de 1863. A pesar de que Castilla fue elegido, aquel hecho marcó la irreversible enemistad entre ambos personajes. El nuevo Congreso establecido el 28 de julio de 1864 trajo como novedad la coexistencia en el parlamento de tres agrupaciones: la «Sociedad Conservadora» del general José Rufino Echenique, el club «castillista» o liberal radical afín al general Castilla y el club político de los partidarios del general Pezet. Estos tres partidos parlamentarios sumados constituían los «dos tercios de todos los diputados con más de 50 por ciento de participación en las votaciones nominales». ${ }^{16}$

La relativa calma en la política se interrumpió el 14 de abril de 1864 cuando se produjo el estallido del conflicto con España derivado de la ocupación de las islas Chincha - vitales en la extracción del guano de las islas - por parte de la escuadra naval del Pacífico comandada por el almirante Luis Hernández-Pinzón. La afrenta a la soberanía nacional reabrió el faccionalismo interno de los partidos parlamentarios que pronto iba a conducir al derrocamiento del régimen de Pezet. La pugna política interna se escenificó entre un poder ejecutivo que prefirió adoptar una política negociadora y conciliadora con la flota naval española y un mayoritario sector del poder legislativo que, de forma visceral y apoyado por una influyente prensa crítica con el gobierno, exigió declarar inmediatamente la guerra a los ocupantes de las islas. ${ }^{17}$

Es en la actuación del parlamento donde puede advertirse la hegemonía adquirida por el discurso belicista opuesto al de la conciliación gubernamental en el diferendo con Espańa. Una vez instalado el Congreso

\footnotetext{
${ }^{15}$ La administración 1867: 37-38.

${ }^{16}$ Mücke 2004: 118.

${ }^{17}$ Para un pormenorizado estudio sobre la evolución de la opinión pública durante el conflicto con España, consultar Chang Huayanca 2011 y 2013.
} 
ordinario fueron elegidos como presidentes del senado y diputados, respectivamente, los generales Castilla y Echenique. La sesión inaugural terminó en un escándalo porque el discurso de Pezet fue contestado de modo bastante virulento por Castilla, bajo cuya presidencia se celebraba la sesión. Este recriminó al presidente por encaminar al país al sometimiento de la «ambición del que a consecuencia de las peripecias de la Soledad, Orizoba y Puebla, pretende imponerle al Perú idéntica suerte que la infortunada México». ${ }^{18}$ Pezet calificó de insultantes las palabras de Castilla y rechazó su pretensión de que el legislativo actuara como máxima instancia estatal en la cuestión con España. Castilla incluso fue agredido verbalmente por el hijo del presidente Pezet que era diputado. ${ }^{19}$ Esta circunstancia provocó el aislamiento del gobierno en el legislativo ya que los congresistas echeniquistas no apoyaron su gestión, aunque tampoco se solidarizaron con la postura de Castilla. Ello explica que a lo largo de la legislatura ordinaria «dos tercios de las votaciones nominales consistían en ataques políticos contra el gobierno. El partido de Echenique era el que generalmente ganaba las votaciones, de tal manera que se puede decir que la Cámara de Diputados era abiertamente opuesta al gobierno». ${ }^{20}$

En la pugna entablada entre el ejecutivo y el legislativo fue triunfando el segundo, y ello se refleja en la censura y caída de los ministros de Pezet que intervinieron en la fase inicial del conflicto hispano-peruano. El gabinete ministerial presidido por Juan Antonio Ribeyro se vio obligado a renunciar el 9 de agosto de 1864 al ser acusado por los diputados echeniquistas del «delito de traición a la confianza pública». El nuevo consejo de ministros fue presidido por Manuel Costas y tuvo a Toribio Pacheco como ministro de Relaciones Exteriores. Este último actuó bajo la consigna presidencial de arreglar «honrosamente» el asunto con España sin omitir la preparación del país para la guerra con la compra de nuevos navíos en Europa. Pero el segundo gabinete de Pezet presentó su renuncia el 14 de octubre de 1864 al no prosperar su pedido de facultades extraordinarias al Congreso para gestionar un empréstito en Londres

\footnotetext{
18 "Congreso». El Comercio. Núm. 8303. Lima, 28 de julio de 1864 (tarde).

${ }^{19}$ Chang Huayanca, 2013: 106.

${ }^{20}$ Mücke 2004: 120.
} 
sobre la garantía de las rentas del guano. Pezet intentó formar su tercer ministerio acordando una alianza con el grupo parlamentario del general Echenique, pero al fracasar la misma se resignó a nombrar un gabinete conservador presidido por el general José Allende y Pedro José Calderón como ministro de Relaciones Exteriores. Al gabinete Allende-Calderón le debió corresponder la defensa ante el Congreso de las bondades del contrato firmado entre el general Vivanco (nombrado por Pezet como ministro plenipotenciario) y el almirante español José Pareja (quien reemplazó a Pinzón como jefe de la expedición naval en diciembre de 1864) por el que se llegó a un acuerdo para poner fin al conflicto.

El contrato Vivanco-Pareja del 27 de enero de 1865 estipuló que las islas Chincha serían desocupadas por los navíos españoles a cambio de que el gobierno peruano cumpliera los compromisos de indemnizar a Espańa con tres millones de pesos por los gastos derivados del conflicto, aceptar a un comisario especial para resolver el asunto de Talambo y acordar el envío de un ministro peruano a Madrid para negociar la liquidación de la deuda peruana con España. Pero Echenique y Castilla, ante la impopularidad con que la prensa y la opinión pública recibieron el tratado Vivanco-Pareja, refrendaron su entendimiento parlamentario antigubernamental y pactaron que el Congreso se clausurara el 1 de febrero de 1865, unas semanas antes de su terminación oficial. Con esta decisión se evitó que los congresistas se implicaran en la eventual aprobación del referido tratado tal como deseaba el gobierno. Se daba la circunstancia de que el nuevo Congreso ordinario legalmente no se podía convocar hasta agosto. Ante este escenario, el presidente rechazó la opción de un Congreso extraordinario y consideró que era responsabilidad del ejecutivo ratificar el tratado, y así lo hizo al día siguiente de la clausura del parlamento. El presidente creyó que el problema estaba solucionado, ya que las islas Chincha fueron devueltas por la escuadra española y la indemnización económica comenzó a hacerse efectiva. Pero, en el corto plazo, el tratado se convirtió en el detonante que provocaría derrocamiento de Pezet. ${ }^{21}$

${ }^{21}$ El tratado Vivanco-Pareja fue el resultado de la necesidad imperiosa de Pezet de recuperar las islas Chincha por ser «la fuente más importante de la renta guanera usada como 
El 5 de febrero se produjo en el Callao el incidente entre los marineros de la escuadra naval espańola que visitaban al prefecto y una enardecida población azuzada por las críticas de la prensa antigubernamental, secundada por los políticos castillistas, echeniquistas y liberales «rojos». Las protestas populares que cuestionaban la firma del «humillante» tratado Vivanco-Pareja produjeron la muerte de un marino español. El almirante Pareja reaccionó indignado y solicitó reparaciones económicas mientras que el gobierno de Pezet destituyó al prefecto. El 6 de febrero el presidente del senado Castilla se presentó en el palacio de gobierno y enrostró al mandatario «su debilidad ante los espańoles y la infamia del tratado» y, según relató el periodista Bernardino León, calificó a Pezet y sus ministros de traidores a la patria. Ante esta acusación el mandatario reaccionó de modo furibundo y, pese a las protestas de la comisión permanente del Congreso, ordenó el destierro de Castilla en un navío que debía conducirlo a Gibraltar. ${ }^{22}$ El castillismo se quedó sin su líder pero en protesta se produjeron varios motines militares que fueron controlados por el gobierno con prisiones preventivas, clausura de periódicos y nuevas expatriaciones. ${ }^{23}$ Este fue el preludio de la revolución que estallaría en Arequipa el 28 de febrero de 1865.

Fueron tres las personalidades militares que lideraron la revolución contra Pezet: el coronel Mariano Ignacio Prado en Arequipa, el coronel José Balta en Chiclayo y el general Pedro Diez Canseco en Ayacucho. Los tres, además de representar a los partidos parlamentarios alzados en armas, tuvieron una amplia influencia en importantes facciones del ejército por ser altos oficiales. Aunque no contaron con la aprobación de sus respectivos líderes Castilla y Echenique, Prado y Diez Canseco acaudillaron a un significativo sector del castillismo mientras que Balta comandó a una facción del echeniquismo. A través de los liderazgos de

garantía de la deuda pública» (Quiroz 2013: 158). Sostiene Quiroz que su ocupación deterioró el crédito peruano al punto tal de dificultar los préstamos en Europa para la compra de buques de guerra.

22 «Prisión del Gran Mariscal D. Ramón Castilla». El Comercio. Núm. 8792. Lima, 12 de noviembre de 1865 .

${ }^{23}$ Arrambide 2018. 
Prado y Balta, los sectores civiles y militares del norte y del sur peruano actuaron coaligados para derrocar al gobernante que desde Lima había «traicionado la causa nacional». El manifiesto revolucionario de Prado suscrito en Arequipa proclamó el cese de Pezet como mandatario de la república por violar la Constitución con la firma del tratado VivancoPareja. Asimismo, declaró a este y a todos sus ministros como reos de alta traición a la patria. Seguidamente, Prado «conforme a la voluntad nacional, fundada en la Constitución política» se proclamó presidente provisorio. El 12 de marzo el vicepresidente Diez Canseco a través de una proclama quitó su apoyo a Pezet y, más bien, declaró que «la actual revolución es la segunda lucha por la independencia del Perú». ${ }^{24}$

La cronología del movimiento revolucionario mostró las dificultades que tuvieron sus tres líderes (Prado, Balta y Diez Canseco) para consensuar su actuación, prueba clara de las discrepancias sobre el sentido que dieron al concepto de revolución los tres líderes de los partidos parlamentarios sublevados contra el gobierno. En marzo de 1865, la revolución se extendió a los principales departamentos del sur (Arequipa, Puno, Ayacucho y Cuzco); en abril, se propagó a todos los departamentos del norte (Cajamarca, Piura, Lambayeque). ${ }^{25}$ Las prefecturas norteñas revolucionadas confirieron a Balta el título de comandante general, constituyeron una junta de gobierno provisional y reconocieron como nuevo gobernante al general Diez Canseco de acuerdo con la Constitución de 1860. Sin embargo, el 25 de abril, en Puno, el coronel Prado se reafirmó como jefe supremo de la república aunque sin exigir a sus aliados del norte su reconocimiento. Esta bicefalia en el liderazgo revolucionario concluyó a fines de junio, cuando Diez Canseco escribió a Prado y le conminó a que «V.E. y su ejército [se pusieran] a mis órdenes, la Patria sabrá apreciar tan noble desprendimiento si no, yo habré cumplido con mi deber y V. E. responderá al país de su conducta». ${ }^{26}$ El legitimismo defendido por Diez Canseco estaba avalado no solo por su condición de

${ }^{24}$ El Peruano. T. 48, núm. 23. Lima, 29 de marzo de 1865.

${ }^{25}$ Márquez 1866: 109-110.

${ }^{26}$ «Crónica interior». El Comercio. Núm. 8690. Lima, 15 de julio de 1865. 
ser una autoridad presidencial elegida democráticamente sino también por haber participado en la redacción de la Constitución de 1860 en calidad de diputado por Arequipa. Prado acató el llamado de Diez Canseco y le entregó el mando del ejército, con lo que transitoriamente unificó a echeniquistas y castillistas, así como a las provincias sublevadas del norte y del sur, bajo un único ejército restaurador.

A diferencia de los revolucionarios, los sostenedores del gobierno constitucional transitaron hacia un irreversible debilitamiento de su fortaleza militar y la pérdida del respaldo de la opinión pública. El ejército controlado por Pezet solo se hizo fuerte en Lima gracias a la llegada de las divisiones procedentes de Junín, Tacna, Trujillo y Chancay, lugares estos que progresivamente fueron ocupados por el enemigo. Pero el apoyo brindado al gobierno por el general Vivanco y sus partidarios se interrumpió con el avance de la revolución. Este renunció como jefe de gabinete y ministro de Guerra a mediados de julio. ${ }^{27}$ También perdió Pezet a su ministro plenipotenciario en Chile y antiguo enemigo de Castilla, el general Fermín del Castillo, quien renunció y se sumó a los revolucionarios del sur. ${ }^{28}$ Mientras tanto, la impopularidad de Pezet se siguió incrementando entre la población al aceptar la negociación con el nuevo mediador español Jacinto Alvistur en su condición de comisario regio. Ese clima de insatisfacción se transformó en euforia con la divulgación en la prensa del decreto del autoproclamado presidente Diez Canseco que desconocía todos los actos de Pezet en relación con el diferendo con España. ${ }^{29}$ El aislamiento del gobierno en Lima fue el preludio de su derrota. El ejército constitucional inició la ofensiva contra los revolucionarios restauradores a fines de octubre al dirigirse a las provincias del sur. Pero el ejército restaurador de Diez Canseco sorprendió a su adversario al no presentar batalla, burlar el ataque y ocupar la capital el 6 de noviembre de 1865. El 8 de noviembre, Pezet partió rumbo a su exilio en París.

${ }^{27}$ El nuevo gabinete presidido por Pedro José Calderón estuvo en función desde el 14 de julio hasta la fecha en que el gobierno fue derrocado.

28 "Crónica interior». El Comercio. Núm. 8714. Lima, 14 de agosto de 1865.

29 «Crónica interior». El Comercio. Núm. 8725. Lima, 28 de agosto de 1865. 
El segundo gobierno interino presidido por el general Diez Canseco duró apenas veintidós días, pero fue suficiente para mostrar la debilidad de la coalición forjada entre las facciones revolucionarias del norte y del sur. El 16 de noviembre, Diez Canseco formó un gobierno mayoritariamente conservador aunque presidido por el liberal Francisco Javier Mariátegui. Balta fue designado ministro de Guerra, mientras que Prado prefirió no asumir ningún ministerio pero en cambio sí la jefatura del ejército. Hasta aquí se mantuvo el consenso y reparto del poder entre los tres. Nuevamente el conflicto con España influyó en la postura irreconciliable en que terminaron enfrascados Diez Canseco y Balta, partidarios de enmarcar el diferendo dentro del marco constitucional, y Prado, afín a que un gobierno dictatorial declarara la guerra a España. Este último impondría su opción belicista sobre la alternativa ceñida a la legalidad defendida por los otros dos líderes revolucionarios. Hábilmente el militar huanuqueño equiparó su pronunciamiento con el sentimiento popular de que la clase política amparada en la Constitución de 1860 había traicionado al país y que era necesario lavar el orgullo herido por la escuadra espańola. Su concepto de revolución se enmarcó no solo como una lucha contra la tiranía de los que actuaban bajo el paraguas de una Constitución fallida sino como un camino simultáneo a la regeneración y a la restauración. ${ }^{30}$ En efecto, la revolución pradista se impuso «echar las bases de una regeneración absoluta en todos los ramos de la administración pública»y, al mismo tiempo, la «restauración de la honra nacional». ${ }^{31}$

Apelando a la doctrina del "pueblo soberano», Prado consideró que los pronunciamientos de las asambleas provinciales que apoyaron su revolución en febrero de 1865 eran su respaldo legal para considerar finiquitada la Constitución de 1860. En esas circunstancias, el vicepresidente Diez Canseco al aferrarse a unos preceptos constitucionales caducados en el lenguaje de los revolucionarios pradistas aceleró la caída de su efímero gobierno. Los altos mandos del ejército, leales a Prado,

\footnotetext{
${ }^{30}$ Aljovín de Losada 2017: 429.

31 Anales 1866: 4.
} 
desconocieron la convocatoria de la elección presidencial y legislativa decretada por Diez Canseco. Según la versión del gobierno provisional deslegitimado, Prado se opuso y «no quería elecciones pues temía, aunque no lo dijera, que el mariscal Castilla pretendiera hacerse elegir una vez más, aprovechando su innegable popularidad, que había crecido últimamente con su deportación y el apoyo que, se juzgaba natural, recibiría de su cuñado [Diez Canseco]». ${ }^{32}$ Con esta actitud de negar su apoyo a un hipotético tercer mandato de Castilla, Prado fracturó definitivamente al partido creado por este y asumió el liderazgo del liberalismo radical. A continuación, este militar auspició una alianza entre su facción y los liberales «rojos» de los hermanos Gálvez. Prado dio un ultimátum a Diez Canseco para que renunciara, pero este se negó a dar tal paso. En consecuencia, el 28 de noviembre de 1865, con el apoyo del ejército, Prado declaró que «el régimen constitucional era incompatible con el programa revolucionario», ${ }^{33}$ desconoció a Diez Canseco y se proclamó jefe supremo provisorio de la nación. En su manifiesto el nuevo gobernante resumió su programa dictatorial en la «realización de los dos fines que se propuso la revolución: salvar a todo trance la honra nacional, y extirpar los abusos que han hecho del Perú el patrimonio de logreros y holgazanes». ${ }^{34}$

\section{GUERRA, DICTADURA Y REVOLUCIÓN}

La dictadura pradista cumplió su promesa de vincular la «salvación de la honra nacional» con los preparativos bélicos en El Callao. Con el apoyo de la opinión pública, Prado invalidó el tratado Vivanco-Pareja por el que el expresidente Pezet «se arrogaba la monstruosa facultad de interpretar la carta constitucional $»^{35} \mathrm{y}$, seguidamente, puso fin a las negociaciones con el comisario español Alvistur. Favorecido por la ruptura diplomática entre Chile y España, el 5 de diciembre de 1865 el régimen peruano acordó con

32 Diez-Canseco 1950: 235.

33 Anales 1866: 6.

${ }^{34}$ Ib.: 8.

${ }^{35}$ Manifiesto 1866: 9. 
su vecino del sur la firma de una alianza defensiva y ofensiva suscrita por sus respectivos plenipotenciarios Pacheco y Santamaría. El 14 de enero de 1866, Perú y Chile procedieron a declarar la guerra a España. Unos días después los gobiernos de Bolivia y Ecuador se sumaron a la firma del tratado e igualmente declararon la guerra a su antigua metrópoli. Al conocer de la declaratoria de guerra por parte de la cuádruple alianza de las repúblicas andinas, la escuadra naval española tuvo una escaramuza bélica con sus enemigos en el estrecho de Abtao (7 de febrero de 1866) y tras ello concentró el bloqueo en Valparaíso. El puerto fue bombardeado e incendiado el 31 de marzo de 1866 e inmediatamente Méndez Núñez dirigió sus navíos de guerra hacia la capital peruana con el propósito de proseguir su acción bélica en el Pacífico.

El combate de El Callao el 2 de mayo de 1866 ha sido considerado por la historiografía peruana como un hito de la unidad y civismo de su población. A pesar de carecer de navíos para enfrentar a una escuadra compuesta por una fragata blindada y siete barcos de menor calado organizadas en tres divisiones, el gobierno de Prado preparó una línea defensiva de baterías, torres y fuertes alrededor del puerto. Relata Arnaldo Márquez que si bien el gobierno sabía que estos medios eran insuficientes para repeler el ataque, se arengó a la población a acudir al puerto para ayudar a los ingenieros, militares y políticos en los trabajos de acondicionamiento de las baterías y de las cañoneras. A continuación, Márquez añadió que, "para honra de la nación, y como elocuente prueba de que solo habían sostenido con las armas al gobierno de 1864, en fuerza de una errada apreciación de sus deberes y no de un sentimiento indigno del patriota y del ciudadano, acudieron en masa militares rendidos el 6 de noviembre, a ofrecer su sangre a la patria en la hora suprema». ${ }^{36}$ Esta aseveración es la única prueba que existe de que los partidarios del general Pezet apoyaron a la dictadura pradista durante el breve conflicto bélico con España. También estuvo presente en el escenario bélico el general Echenique. En cambio, Diez Canseco y Balta ocuparon un lugar muy marginal en la contienda bélica. En 1867, un apologista de Balta 
calificó de temeraria la estrategia de combate dispuesta por el dictador. Proclamando que las «glorias de mayo» pertenecían exclusivamente al pueblo y no a Prado, este concluyó que «si esta función de armas se hubiera librado bajo el régimen constitucional, con Balta como ministro de Guerra, y Castilla como general en jefe, otro y muy distinto y más espléndido habría sido el resultado». ${ }^{37}$

El combate supuso para España perder dos naves de guerra y para el Perú la desactivación de buena parte de sus baterías y cañones debido al bombardeo. ${ }^{38}$ En la batería de la Merced la muerte sorprendió al secretario Gálvez, con lo que los liberales «rojos» perdieron a su máximo líder. El inmediato retorno de la escuadra del almirante Méndez Núñez a España puso fin al conflicto bélico del Pacífico iniciado en 1864. Para Prado, una vez concluida la guerra, había llegado la hora de sacar rédito a su apuesta belicista que se calificó en la prensa y en la opinión pública como una inobjetable jornada victoriosa. El 2 de mayo no tardó en transformarse en un referente nacionalista al ordenarse, como importantes recordatorios, la construcción de un monumento público y de un hospital que, con su nombre, perennizaran la efemérides, y rebautizarse la Sociedad Fundadores de la Independencia también como Vencedores del 2 de mayo de $1866 .{ }^{39}$ A todo ello se debe agregar que «el panteón de los héroes se enriqueció con peruanos anónimos personificados en la figura incuestionada de José Gálvez». ${ }^{40}$ El discurso pradista convirtió al malogrado líder liberal «rojo» en ícono de su ideario revolucionario al decretar que su busto se colocase en la cúspide del futuro monumento. Según el decreto, la memoria del acontecimiento realzada con la inmolación de Gálvez «merece ser perpetuada en un monumento que las generaciones venideras contemplen las virtudes cívicas de la presente y aprendan a preferir la muerte a la deshonra».. ${ }^{41} \mathrm{El}$ discurso nacionalista del pradismo logró su objetivo de perennizar el 2 de mayo

\footnotetext{
${ }^{37}$ El Manifiesto 1867: 17.

${ }^{38}$ García Martínez 1994 y Romero Pintado 1984.

${ }^{39}$ Martínez Riaza 2004.

${ }^{40} \mathrm{Ib} .: 397$.

${ }^{41}$ Márquez 1866: 2, 113.
} 
como la segunda fecha de la independencia de España, hermanándola con 1821. Ahora bien, si el nuevo imaginario patriótico promovido por la dictadura tuvo un innegable éxito popular, ¿por qué el pradismo sucumbió apenas un año después? La respuesta hay que encontrarla en las medidas políticas encaminadas a convertir al liberalismo pradista en un partido parlamentario no solo hegemónico sino, de ser posible, con los adversarios neutralizados.

Prado instauró la dictadura en medio de una grave crisis económica derivada del despilfarro y la corrupción generados por las rentas del guano y la deuda abultada con los consignatarios europeos del producto relacionados con el adelanto de préstamos al Estado. ${ }^{42}$ El gobierno dictatorial apenas se estableció quiso afrontar este problema promoviendo una drástica reducción de los gastos públicos. Esta decisión afectó de modo directo a los supuestos beneficiarios del gobierno destituido. Esta ofensiva comenzó en diciembre de 1865, cuando Prado por decreto dejó sin efecto «todos los títulos y ascensos militares conferidos por el gobierno del exgeneral Don Juan Antonio Pezet, desde el 7 de marzo [de 1865]». ${ }^{43}$ Esta medida se complementó con la eliminación del escalafón general del ejército de los altos mandos que sirvieron al ejército constitucional.

Las represalias políticas amparadas en la austeridad económica se trasladaron al parlamento. Prado consideró escandaloso el aumento de las secretarías de las cámaras de diputado y senadores en las últimas legislaturas. Por ello suprimió todos esos empleos y dispuso que el cuidado de los archivos del Congreso recayera en un solo oficial. ${ }^{44}$ A todo ello se sumó la anulación de todos los ascensos, empleos, cargos o beneficios conferidos por el derrocado mandatario a los diputados y senadores de su última legislatura, «disposición [que] comprende los ascensos obtenidos en cualquier carrera pública». ${ }^{45}$ La persecución a los pezetistas se extendió a las administraciones provinciales y tesorerías departamentales, a cuyos

${ }^{42}$ Para estudios sobre la crisis del guano en la década de 1860, véase Tantaleán Arbulú 1983 y Contreras 2004.

${ }^{43}$ Anales 1866: 79.

${ }^{44} \mathrm{Ib} .: 22-23$.

${ }^{45}$ Ib.: 74 . 
responsables se conminó a denunciar todo anticipo, comisión, remuneración o gratificación que se hubiese entregado a los jefes y oficiales del ejército y armada constitucionales, para proceder a su reclamación.

Ninguna de las anteriores medidas superó como mecanismo de castigo ejemplar al establecimiento de una corte central punitiva. Esta inédita instancia jurídica, solo comparable con el Tribunal de la Acordada establecido en 1835, fue constituida el 6 de diciembre de 1865 bajo el considerando de que uno de los objetivos de la revolución fue el juicio y castigo de las autoridades que celebraron tratados que dañaron la honra nacional y las garantías nacionales y, también, de quienes participaron en actos de peculado o malversación de caudales públicos. En la medida que la corte debía satisfacer «la vindicta pública», o castigo político ejemplarizante, el decreto de su creación procedió a reglamentar la actuación de sus siete vocales y dos fiscales. A ellos se les impuso tramitar las denuncias contra los funcionarios públicos que hubiesen participado en tratados «con mengua de la honra nacional y gravamen del erario público». ${ }^{46}$ La medida se amplió a todos los empleados comprendidos en denuncias de cohecho y lucro personal con las rentas del Estado. El 13 de diciembre, día del establecimiento formal de la corte central, el secretario de gobierno, policía y obras públicas, José María Quimper, comunicó a todos los prefectos que "procedan a aprehender y remitir a esta capital a todas las personas comprendidas en los diferentes incisos ${ }^{47}$ del decreto. Los juicios se celebraron en el salón donde sesionaba el senado.

Desde su destierro, Pezet calificó a la corte central de «tribunal revolucionario» y denunció que los jueces que la integraban eran íntimos partidarios del régimen pradista cuya función no era juzgar sino, más bien, condenar: «si el fallo de la corte central no estaba de acuerdo con las acusaciones, los revolucionarios aparecían como unos calumniadores y la revolución como un calumnioso pretexto». ${ }^{48}$ Ante la tesitura de estar condenados antes de celebrarse su juicio, varios de los acusados

\footnotetext{
${ }^{46}$ Ib.: 41.

${ }^{47}$ Ib.: $70-71$.

${ }^{48}$ Exposición 1867: 124.
} 
se exiliaron en países limítrofes. Entre los que no pudieron huir y enfrentaron el proceso, muchos fueron condenados, aunque en casos «seguidos por robos y dilapidaciones, se ha visto la corte central tan embarazada, que ha tenido que ceder a la fuerza de la verdad y sobreseer en el juzgamiento». ${ }^{49}$ Pezet recibió noticias de que algunos de sus ministros habían sido condenados por supuestos robos al tesoro «sin que les fuera posible explicar o probar la inversión de esa suma». ${ }^{50}$ Irónicamente, concluyó Pezet: «felices debemos considerarnos porque no se nos haya condenado a muerte, vista la indignación con que los jueces, en el considerando cuarto de la sentencia, declaran que para la enormidad de nuestros crímenes, no existía en los códigos peruanos pena suficiente». ${ }^{51}$

La polémica actuación de la corte central le restó credibilidad a un gobierno que ya se encaminaba hacia la impopularidad tras haber promulgado la ley de contribución personal. Esta capitación debía ser pagada por todos los varones comprendidos entre los 21 y 60 años en dos semestres (junio y diciembre). Carlos Contreras recuerda que el secretario de Hacienda Manuel Pardo hizo un cálculo de que la recaudación generaría un ingreso de hasta 1,8 millones de soles al ańo; sin embargo, «todo el rubro de contribuciones directas (además de la del jornal, las de predios, patentes e industrias) produjo en 1866 la cifra de 631.277 soles». ${ }^{52}$ La resistencia y el descontento de los contribuyentes fue tal que el Congreso constituyente de 1867 tuvo que abolir el 15 de marzo la contribución personal.

El 28 de julio de 1866, el dictador expidió el decreto de convocatoria de un Congreso constituyente cuya instalación se fijó para el 15 de febrero de 1867. El parlamento iba nuevamente a reunirse tras un prolongado receso ya que su última sesión se produjo exactamente dos años antes. Ahora la asamblea debía promulgar una nueva Constitución —o «designar de las preexistentes la que deba regir» en alusión a la carta política liberal de 1856 - y elegir al nuevo presidente de la república a partir del escrutinio de los sufragios emitidos en los colegios provinciales.

${ }^{49}$ Ib.: 124.

${ }^{50} \mathrm{Ib}$.

51 Ib.: 125 .

${ }^{52}$ Contreras 2005: 92. 
Esta asamblea integrada por 101 diputados debía sesionar durante cien días, pero tal plazo fue posteriormente ampliado por otro decreto presidencial hasta noviembre de 1867. El artículo 8 del reglamento electoral consideró incompatible el ejercicio de la representación nacional con todo empleo público por lo que el diputado electo debía renunciar a la condición de empleado.

El dictador, en su empecinado proyecto de convertirse en mandatario constitucional, enfrentó a dos adversarios a quienes no tardó en calificar de conspiradores: Balta y Castilla. Mientras el primero impuso que en el parlamento el conservadurismo tuviera presencia, el segundo procuró convencer al gobernante de que la única legalidad admisible era el restablecimiento de la Constitución de 1860. Balta decidió enfrentarse en las urnas a Prado pero, en vísperas de iniciarse la votación, publicó una proclama en la que enfatizó que «después del 28 de noviembre [de 1865], entre el Gobierno y yo no hay vínculo posible». ${ }^{53}$ Esta afirmación fue calificada como una amenaza y fue el pretexto aducido por el gobierno para su detención y deportación junto a decenas de militares y civiles conservadores. Desde su exilio en Santiago de Chile, Balta auspició a través de un colaborador anónimo la publicación de un Manifiesto en donde justificó el contenido de su proclama como una reacción a la actuación arbitraria del régimen pradista que había conducido al «naufragio de las libertades». El Manifiesto criticó, primero, la reforma judicial que sometió los procesos políticos en la corte central a la parcialidad de un fiscal que actuaba de acuerdo con el gusto del gobierno; segundo, la pérdida de la autonomía de las municipalidades al subordinarlas a los prefectos y subprefectos; tercero, el sometimiento del Congreso constituyente a las candidaturas ministeriales; y cuarto, la imposición de impuestos solo a la producción nacional y la creación de la anacrónica contribución personal «faltando a los más triviales principios económicos». ${ }^{54} \mathrm{El}$ Manifiesto no activó ninguna revolución al carecer los conservadores de las provincias del norte de un líder similar a Balta.

53 «Crónica interior». El Comercio. Lima, 23 de octubre de 1866.

${ }^{54}$ El Manifiesto 1867: 13. 
Alejado este último de la confrontación electoral, el retorno del general Castilla de su exilio, el 17 de mayo de 1866, se constituyó en el mayor riesgo para la perpetuación del régimen. Según Vargas Ugarte, "Castilla es partidario de que Prado entregue el mando a su cuñado D. Pedro Diez Canseco y éste es el partido que abraza». ${ }^{55}$ Esta afirmación confirma que Castilla, al invocar la restauración constitucional, aspiraba a que Prado devolviera el mando supremo al segundo vicepresidente surgido de la última elección presidencial de 1862. Pero al reafirmarse Prado en su intención de legalizarse en el poder con una nueva Constitución respaldada por gran parte del liberalismo cooptado, Castilla no dudó en romper políticamente con él. No solo declinó la oferta del dictador de asumir la representación diplomática en Francia sino que optó por retirarse a Tarapacá a complotar. Castilla se convirtió en un enemigo potencial y peligroso debido a su arraigo sobre los militares descontentos con las represalias de Prado. Por eso, en el transcurso de la campaña electoral, el expresidente fue apresado bajo el cargo de conspiración y se le expulsó a Chile. En este país, Castilla asumió el liderazgo de su tercera revolución, cuyo objetivo esta vez consistió en insurreccionar a los pueblos del sur del Perú contra Prado y restaurar la Constitución de 1860. Pero el 30 de mayo de 1867, ya con el Congreso constituyente establecido, la muerte sorprendió a Castilla en plena actividad revolucionaria. Prado quiso aprovechar el funeral oficial dedicado al expresidente para alcanzar una amnistía y reconciliación política entre los liberales pero fracasó en su empeño.

Si Prado creyó que con el exilio de Balta y con la muerte de Castilla cesarían las protestas en su contra, su cálculo no pudo ser más errado. Los miembros del ejército perjudicados con el desconocimiento de sus promociones y ascensos bajo el gobierno derrocado se convirtieron en carnaza de los complots. Al comenzar 1867 muchos de ellos se transformaron en agentes de la revolución antiliberal y, por ese motivo, fueron expulsados, «esta vez al norte, los coroneles Domingo Gamio y Francisco Goyzueta, quienes fueron previamente borrados del escalafón militar; al mismo tiempo eran expatriados los coroneles Ramón Vargas Machuca y

${ }^{55}$ Vargas Ugarte 1971, IX: 129. 
Andrés Segura y la futura gloria literaria nacional D. Ricardo Palma». ${ }^{56}$ No menos tensa era la relación del gobierno con la marina: en octubre de 1866 la renuncia colectiva de una parte del alto mando naval en protesta por el nombramiento del comodoro estadounidense John Randolph Tucker como jefe de la escuadra peruana motivó su enjuiciamiento por insubordinación. Lizardo Montero, Miguel Grau, entre otros, fueron procesados por un tribunal militar en enero de $1867 \mathrm{y}$, a pesar de ser absueltos, «la mayor parte de estos oficiales fueron a servir en las compañías de navegación privadas y muchos de ellos se convirtieron en activos agentes revolucionarios». ${ }^{57}$

La mayor parte de los representantes electos al Congreso extraordinario de 1867 correspondieron al pradismo y a los liberales «rojos». ${ }^{58} \mathrm{La}$ presidencia de rotación mensual de la asamblea la ejercieron, sucesivamente, Antonio Salinas, José María Quimper, José Jacinto Ibarra (en cuatro ocasiones), Mariano Herencia Zevallos y Francisco García Calderón. El 15 de febrero de 1867, el Congreso aceptó la dimisión de Prado en el mando supremo de la nación, pero inmediatamente le nombró presidente provisorio de la república. El camino para hacer una Constitución liberal similar a la de 1856 se inició con el restablecimiento del Estatuto Provisorio de la Convención Nacional del 27 de julio de 1855 que debía regir como máxima norma legal hasta la promulgación de la nueva carta política. Por último, la comisión especial designada por la asamblea para calificar las elecciones presidenciales emitió el 28 de agosto de 1867 el dictamen esperado por el gobernante para legitimarse como mandatario constitucional: «que no había encontrado causa de nulidad ni vicio alguno en el proceso electoral presidencial y que de los 204,818 votos que habían favorecido a veintitrés candidatos a la Presidencia de la República, el coronel Prado obtuvo 199.499 sufragios en su favor». ${ }^{59}$ Con este resultado lo que quedaba demostrado era que el control gubernamental de las mesas electorales en las provincias había sido casi absoluto.

\footnotetext{
${ }^{56}$ Diez Canseco 1950: 251.

${ }^{57}$ Ib.: 252.

${ }^{58}$ García Bedoya 1954: 18-21.

${ }^{59} \mathrm{Ib} .: 3$.
} 
El Congreso de 1867 tuvo una inicial fase de actuación complaciente con el ejecutivo, pero las primeras discrepancias entre ambos poderes como efecto de la delicada cuestión religiosa no tardaron. Basadre señala que dentro de este problema estuvieron incluidos el proyecto de Fernando Casós sobre la desamortización de bienes eclesiásticos que fue rechazado, el debate sobre libertad de cultos que fracasó y el artículo constitucional sobre libertad de enseñanza en las escuelas primaria, media y superior y libre creación de universidades que fue aprobado. ${ }^{60}$ Pero mientras los legisladores se empecinaron en recobrar el espíritu liberal de 1856, Prado, en su afán de congraciarse con la alta jerarquía eclesiástica, adoptó una postura distante con relación a los ataques de su agrupación parlamentaria a los privilegios de la iglesia. Como consecuencia, su distanciamiento con el legislativo se hizo irreversible. Esta separación se hizo visible como resultado de los incidentes ocurridos en Lima en abril cuando una turba popular católica atacó a varios diputados liberales cerca al Congreso. Como resultado de este hecho, el 11 de abril el gabinete ministerial Bustamante, en el que destacaba como ministro de Justicia y Culto el obispo Tiberiópolis, ${ }^{61}$ tras abandonar el parlamento luego de una tumultuosa interpelación fue censurado por no «contener y castigar a los que habían atentado contra la majestad del Congreso». El divorcio entre el gobierno y el Congreso se consolidó el 24 de abril cuando este último aprobó un proyecto de ley sobre el voto de censura, el mismo que impedía al presidente despachar con ministros censurados, lo que implicó que todos los actos del gabinete Tiberiópolis fuesen declarados nulos y este no tuviera más remedio que renunciar. Como señala Basadre, "por primera vez en el Perú cayó así un gabinete ministerial, derribado por el Congreso». ${ }^{62}$

El 23 de mayo, en una sesión secreta, el presidente provisorio solicitó al Congreso adelantar la promulgación de la Constitución y conferirle poderes extraordinarios para combatir la revolución del general Castilla.

\footnotetext{
${ }^{60}$ Basadre 1963-1964, IV: 1653-1654.

${ }^{61}$ Elguera Valega 2002.

${ }^{62}$ Basadre 1963-1964, IV: 1657.
} 
Era evidente la incomodidad del ejecutivo con un poder legislativo que había dejado de ser condescendiente. El presidente del Congreso Ibarra ofreció debatir ambos asuntos. En cuanto al primer pedido, los congresistas desecharon promulgar la carta política el 28 de julio como había sido su intención original y prolongaron sus sesiones tres meses más. ${ }^{63}$ En el caso del último pedido, el fallecimiento de Castilla hizo innecesaria su discusión en el Congreso. Los diputados más bien, contrariando a Prado, asumieron el deber de ocuparse de los funerales del expresidente con el levantamiento de un mausoleo de mármol en su recuerdo. Durante estos meses no cesaron las interpelaciones a los ministros, en el que tuvo un protagonismo central el diputado liberal Casós, que provocaron la incomodidad del presidente Prado.

El Congreso promulgó la nueva Constitución el 29 de agosto de 1867, la misma que iba a estar vigente hasta su abolición el 6 de enero de 1868 . Como resultado de la crisis generada por los levantamientos armados conservadores que estallaron en varias provincias del norte y del sur en contra de una Constitución calificada de anticatólica, la confrontación entre el ejecutivo y el legislativo, lejos de cesar, se agudizó. El 25 de septiembre el ministro de Gobierno fue interpelado sobre la revolución estallada en Arequipa. Este respondió que la sublevación no solo se hizo contra el ejecutivo sino también contra el Congreso, por lo que solicitó a los diputados colaborar con el gobierno para restablecer el orden. Pero el Congreso hizo oídos sordos a lo expresado por el ministro y aplazó la autorización de poderes extraordinarios solicitada por el mandatario para combatir la revolución arequipeña. La ruptura entre el legislativo y el ejecutivo se produjo el 4 de octubre cuando el gobierno decretó la prisión por conspiración del congresista por Cuzco, Mariano Herencia Zevallos. Los diputados acordaron por mayoría convocar al ministro de Gobierno para desaprobar la violación del fuero parlamentario. Poco después, al conocerse la partida del presidente Prado al sur para debelar la rebelión del general Pedro Diez Canseco sin autorización del Congreso, veintitrés representantes firmaron un documento en el que

${ }^{63}$ García Bedoya 1954: 195. 
acordaron no concurrir más al recinto parlamentario "hasta que se halle pacificada la República». ${ }^{64}$

El conflicto institucional fue a mayores cuando el presidente de la asamblea, Francisco García Calderón, lanzó la idea de que al haber quebrantado la Constitución el mandatario, la presidencia había vacado y que debía ser el general Luis La Puerta, en su condición de mandatario interino, quien asumiera el cargo. ${ }^{65}$ García Calderón hizo constar que el Congreso, al despojar del poder al presidente, no apoyaba implícitamente al general Diez Canseco, porque consideraba que su legitimidad como autoridad «era dudosa».66 Esta propuesta fue aprobada por 46 diputados, quienes suscribieron que el general La Puerta debía nombrar una comisión de vecinos notables para parlamentar con Prado y García Calderón con el propósito de que ambos depusieran las armas, se retiraran al extranjero y se procediese a celebrar una nueva elección presidencial. ${ }^{67}$ Pero el vicepresidente interino declinó liderar el plan de García Calderón y con ello la implicación del partido parlamentario en la revolución concluyó. El 15 de noviembre de 1867, los representantes que aún asistían al Congreso, un total de cuarenta y tres, dieron por concluida su actividad.

Mariano Ignacio Prado, Pedro Diez Canseco y José Balta fueron nuevamente el trío protagonista de la última escenificación de la violencia en la política peruana a fines de la década de 1860, esta vez no como aliados sino enfrentando el primero al segundo y tercero. La revolución conservadora liderada por el general Pedro Diez Canseco que estalló en Arequipa el 22 de septiembre de 1867 adujo el rechazo popular a una Constitución calificada de «impía». En el pronunciamiento redactado en cabildo abierto se proclamó la restauración de la Constitución de 1860, instrumento legal que permitió la proclamación de la presidencia de Diez Canseco por ser el último gobernante elegido bajo la máxima ley política. Diez Canseco se rodeó de las más influyentes figuras del conservadurismo católico arequipeño, como Juan Manuel Polar,

\footnotetext{
${ }^{64} \mathrm{Ib} .: 8$.

${ }^{65} \mathrm{Ib} .:$. 9.

${ }^{66} \mathrm{Ib} .: 211$.

${ }^{67}$ Ib.: 211-212.
} 
Fernando Alvizuri y Francisco Chocano, es decir «los antiguos rebeldes de todas las revoluciones de Arequipa, a cuyo lado empezaban a figurar los nuevos jóvenes elementos». ${ }^{6}$

Prado, con parte del ejército, se embarcó a mediados de octubre con dirección al sur para contener a los revolucionarios arequipeños que habían extendido su dominio también sobre el departamento de Puno. El sitio de la capital arequipeña, tal como ocurriera en 1858, implicó un bombardeo continuo de sus defensas, pero Prado fracasó en su propósito de rendir a la población. Tras el frustrante asalto de la ciudad el 27 de diciembre de 1867, al advertir que otra revolución conservadora se extendía en los departamentos del norte bajo el liderazgo del coronel Balta, el presidente ordenó el repliegue de sus fuerzas a la capital. Al igual que en Arequipa, el pronunciamiento de Balta expedido en Cajamarca en noviembre de 1867 calificó a Prado de gobernante usurpador, rechazó la nueva Constitución por antirreligiosa, afirmó la defensa de la religión católica y proclamó la vigencia de la Constitución de 1860, con lo que se reconoció la legalidad de la presidencia del general Diez Canseco. Las fuerzas baltistas repelieron con éxito el ataque de las tropas gubernamentales a Chiclayo el 5 de enero de 1868. La caída del gobierno se hizo inevitable cuando Prado fue informado de que en Lima el general Francisco Diez Canseco había asumido el mando como jefe político y militar del centro, plegándose a la revolución liderada por su hermano en Arequipa. Ante su aislamiento, Prado renunció el 10 de enero de 1868 y tomó el rumbo del exilio a Chile.

El triunfo de la revolución conservadora de 1867 trajo como consecuencia la restauración de la Constitución de 1860. Diez Canseco asumió por tercera vez la presidencia provisoria pero, pese a ser propuesta su candidatura presidencial, optó por no participar en la contienda electoral de febrero de 1868, en la que resultó triunfador José Balta. El resultado electoral confirmó el desplazamiento de los clubes electorales parlamentarios surgidos en los años cincuenta. El Congreso validó el triunfo del club conservador de Balta, que absorbió parte de la desaparecida sociedad 
electoral echeniquista, con el $86 \%$ de los votos escrutados. La candidatura civil de Manuel Toribio Ureta representando a los liberales apenas obtuvo 153 votos. La desaparición de los partidos echeniquista, castillista, pezetista y pradista del parlamento fue la consecuencia inevitable de una década caracterizada por el enfrentamiento crónico entre el ejecutivo y legislativo, marcado por la guerra internacional con Espańa y siguiendo una lógica de responder a la exclusión política con la praxis revolucionaria.

\section{BIBLIOGRAFÍA}

Aljovín de Losada, Cristóbal. 2010. «Entre la unidad y la pluralidad. El concepto de partido-facción en el Perú 1770-1870». Boletín del Instituto Francés de Estudios Andinos. T. 39, núm. 1: 63-84.

.2014. «Elecciones y oficiales del ejército: Perú 1827-1896». Journal of Iberian and Latin American Research. Vol. 20, núm. 1: 50-65.

. 2017. «Revolución 1770-1870». En Cristóbal Aljovín de Losada y Marcel Velázquez Castro (comps.), Las voces de la modernidad. Perú, 1750-1870. Lenguajes de la independencia y la República. Lima: Fondo Editorial del Congreso del Perú, 415-433.

Anales de la Dictadura. Colección de documentos oficiales de la jefatura suprema del coronel Mariano I. Prado, Noviembre 28 de 1865. 1866. Lima: Imprenta de El Nacional.

Arias-Schreiber Pezet, Jorge. 1963. El general Juan Antonio Pezet: Presidente de la república del Perú (1863-1865). Lima: Imprenta FAP.

Arrambide, Víctor. 2018. «Prensa y revolución: los periódicos durante las guerras civiles de 1865 y 1867». En Carmen Mc Evoy y Alejandro Rabinovich (eds.), Tiempo de guerra. Estado, nación y conflicto armado en el Perú, siglos XVII-XIX. Lima: Instituto de Estudios Peruanos, 335-363.

Basadre, Jorge. 1963-1964. Historia de la República del Perú. Lima: Editorial Peruamérica, 7 vols.

Benvenuto, Neptalí. 1906-1955. Crónica parlamentaria del Perú. Historia de los congresos que han funcionado en la República desde 1822. Lima: Imprenta Americana, 11 vols.

Chang Huayanca, Antonio José. 2011. «La opinión pública formada en el Perú durante el conflicto diplomático con Espańa: El ocaso del régimen del Gral. Pezet (1863-1866)». Illapa. Núm. 8: 139-152.

2013. Entre la espada y la pared. La administración del gral. Juan Antonio Pezet frente a la crisis diplomática con España (1863-1865). Tesis de Bachiller. Lima: Universidad Nacional Mayor de San Marcos. 
Constitución y leyes orgánicas del Perú dadas por el Congreso de 1860. Comparadas con las que sancionó la Convención Nacional de 1855. 1863. Lima: Imprenta del Mercurio.

Contreras, Carlos. 2004. El aprendizaje del capitalismo. Estudios de historia económica y social del Perú republicano. Lima: Instituto de Estudios Peruanos.

. 2005. «El impuesto de la contribución personal en el Perú del siglo XIX». Histórica. Vol. XXIX, núm. 2: 67-106.

Diez Canseco, Ernesto. 1950. Los generales Diez Canseco. Lima: Imprenta Torres Aguirre.

El Manifiesto del coronel Balta. 1867. Santiago: Imprenta del Ferrocarril.

Elguera Valega, Luis. 2002. «El conflicto entre el Congreso Constituyente de 1867 y el gabinete Tiberiópolis en el origen de la eficacia legal del voto de censura en el Perú». Pensamiento Constitucional. Año VIII, núm. 8: 695-715.

Exposición del general don Juan Antonio Pezet ex presidente del Perú. 1867. París: Imprenta Parisiense L. Berger y Comp.

García Bedoya, Telésforo. 1954. Anales del Congreso del Perú 1865-1867. Lima: Edición Oficial del Congreso.

García Martínez, José Ramón 1994. El combate del 2 de mayo de 1866 en el Callao. Madrid: Editorial Naval.

Gentile, Jorge Horacio (comp.). 2008. El poder legislativo. Aportes para el conocimiento del Congreso de la Nación Argentina. Montevideo: Fundación Konrad Adenauer y Asociación Argentina de Derecho Constitucional.

Irurozqui, Marta. 2018. "El legislativo asalta los cielos. El liberalismo a través del Congreso Constituyente de 1839». En Ivana Frasquet y Encarna García Monerris (eds.), Tiempo de politica, tiempo de constitución. La monarquia hispánica entre la revolución y la reacción (1780-1840). Granada: Comares Historia, 137-161.

La administración del general Pezet en la república del Perú. 1867. París: Imprenta Parisiense Guyot y Scribe.

Manifiesto de los motivos que han inducido al Perú a declarar la guerra al gobierno de España. 1866. Lima: Edición oficial.

Márquez, Arnaldo. 1866. El Perú y la España moderna. Lima: Imprenta de El Nacional.

Martínez Riaza, Ascensión. 2004. «El Dos de mayo de 1866. Lecturas peruanas en torno a un referente nacionalista (1860-1890)». En Carmen Mc Evoy (ed.), La experiencia burguesa en el Perú (1840-1940). Madrid y Frankfurt: Iberoamericana y Vervuert, 391-419.

Mc Evoy, Carmen. 1996. «El legado castillista». Histórica. Vol. XX, núm. 2: 211-224.

Mücke, Ulrich. 2004. «Los patrones de votación y el surgimiento de los partidos parlamentarios en el Congreso del Perú, 1860-1879». Investigaciones Sociales. Núm. 13: 111-133. 
Peralta Ruiz, Víctor. 2013. «La guerra civil peruana de 1854. Los entresijos de una revolución». Anuario de Estudios Americanos. Vol. 70, núm.1: 195-219.

2018. "Las revoluciones del general Manuel Ignacio de Vivanco, 18411858». En Carmen Mc Evoy y Alejandro Rabinovich (eds.), Tiempo de guerra. Estado, nación y conflicto armado en el Perú, siglos XVII-XIX. Lima: Instituto de Estudios Peruanos, 249-275.

Pinto Vallejos. Julio. 2016. «La construcción social del Estado en el Perú: el régimen de Castilla y el mundo popular, 1845-1856». Historia. Núm. 49: 547-578. https://doi.org/10.4067/s0717-71942016000200008

Quiroz, Alfonso. 1987. La deuda defraudada: consolidación de 1850 y dominio económico en el Perú. Lima: Instituto Nacional de Cultura.

. 2013. Historia de la corrupción en el Perú. Lima: Instituto de Estudios Peruanos e Instituto de Defensa Legal.

Rabasa, Emilio. 1999. La constitución y la dictadura. Estudio sobre la organización politica de México. Comité de Asuntos Editoriales Cámara de Diputados.

Ragas Rojas, José. 2003. Ciudadanía, cultura política y representación en el Perú: La campaña electoral de 1850. Tesis de Licenciado en Historia. Lima: Pontificia Universidad Católica del Perú.

Romero Pintado, Fernando. 1984. Historia Marítima del Perú, t. VIII, vol. 2: La República (1850-1870). Lima: Instituto de Estudios Histórico Marítimos.

Saldaña Lagos, Catalina. 2010. «Estallidos provinciales. La tensa relación entre las provincias y el centro. Chile, 1830-1860». Revista Universum. Vol. 1: 174-186. https://doi.org/10.4067/s0718-23762010000100012

Sobrevilla Perea, Natalia. 2005. «Batallas por la legitimidad: Constitucionalismo y conflict en el Perú del siglo XIX (1812-1860)». En Paulo Drinot y Leo Garofalo (eds.), Más allá de la dominación y la resistencia. Estudios de historia peruana, siglos XVI-XX. Lima: Instituto de Estudios Peruanos, 181-214.

.2017. «Power of the law or power of the sword: The conflictive relationship between the executive and the legislative in Nineteenth-century Peru». Parliaments, States and Representation. Vol. 37, núm. 2: 220-234. https://doi.org/10 $.1080 / 02606755.2017 .1334326$

Tantaleán Arbulú, Javier. 1983. Política económico-financiera y la formación del Estado, siglo XIX. Lima: Centro de Estudios para el Desarrollo y la Participación.

Távara, Santiago. 1951. Historia de los partidos. Edición y notas de Jorge Basadre y Féliz Denegri Luna. Lima: Editorial Huascarán.

Vargas Ugarte, Rubén. 1971. Historia general del Perú. Lima: Editor Carlos Milla Batres, 10 vols.

Fecha de recepción: 10/I/2018 Fecha de aceptación: 13/III/2018 